\title{
PRESENTACIÓN
}

\section{La institucionalización del Estado en América Latina. Justicia y violencia política en la primera mitad del siglo $\mathrm{XIX}^{1}$}

\author{
Marta IRUROZQUi VictoRIANO \\ GEA, IH-CSIC \\ marta.irurozqui@cchs.csic.es
}

"Solo el presente tiene una forma inmutable, inflexible, el pasado es lo que elegimos hacer de él. Nuestro presente moldea la historia, no al revés."

Craig Russel, Muerte en Hamburgo, p. 138

Con el estudio de la impronta de la justicia y la violencia política en el proceso de institucionalización del Estado en América Latina a lo largo del siglo XIX, este dossier se suma a dos publicaciones anteriores sobre el mismo tema: un dossier sobre la violencia política coordinado por Marta Irurozqui en Revista de Indias $\left(\mathrm{n}^{\circ} 246,2009\right)$ y una edición dirigida por Marta Irurozqui y Mirian Galante, Sangre de ley. Justicia y violencia política en la institucionalización del Estado en América Latina, siglo XIX (Madrid, Ed. Polifemo, 2011). En las tres publicaciones subyace la discusión sobre cómo y por qué la democracia ha terminado por entenderse en la actualidad como el imperio del estado de derecho -en su sentido más formal ${ }^{2}$ - en vez de como el triunfo de la soberanía popular.

¿Por qué se consideran los fenómenos de la justicia y la violencia política centrales en la configuración institucional de las nuevas repúblicas y por qué trabajarlos de un modo conjunto y relacionado? En primer lugar se busca cuestionar la perspectiva unilateral que tradicionalmente veía en la justicia y la violencia política los polos positivo y negativo del diseño nacional, al hacer de la primera un correctivo de la segunda y al identificar a ésta como la responsable del "desgobierno latinoamericano".

\footnotetext{
${ }^{1}$ Proyectos de investigación I+D: HUM2006-10136 y HAR2010-17580.

${ }^{2}$ Una buena aproximación en español a la discusión sobre la consideración formal o sustantiva del Estado de derecho, así como algunas de las posturas de los representantes de la misma en CARBonelL - Orozco - VÁzQuez, 2002.
} 
A esa antítesis entre la fuerza y el derecho se opone una perspectiva relacional entre violencia y ley para tratar de comprender en toda su complejidad las dinámicas de creación institucional. Se entienden ambos fenómenos como un binomio polifacético que interactuaba constantemente dentro de la sociedad para hacer posible su vida política, posibilitando con ello el asentamiento estatal. Se sostienen tres argumentos al respecto. Primero, la existencia de la justicia como un principio ordenador del pueblo soberano podía hacerse posible a través del ejercicio público de la violencia, siendo reconocido éste por la sociedad como un derecho y un deber constitucionales. Segundo, a través de la ley -en su doble versión de jurisprudencia y legislación- quedaban legitimados en el plano ideológico actos públicos que solamente la fuerza justificaba, al tiempo que se invisibilizaba, en aras de la construcción nacional, la contingencia política de la ley y la función ideológica del derecho. Y, tercero, las demandas de justicia y la exigencia al Estado de su intervención en la resolución de los conflictos entre particulares y de éstos con las instituciones se asumían como ejercicios de ciudadanía.

En segundo lugar, se apuesta por comprender los procesos sociales atendiendo prioritariamente a los contextos y no al encorsetamiento categórico. En absoluto se desestima el recurso teórico, sino una sumisión al mismo que obligue a abordar las realidades políticas y sociales a partir de modelos analíticos ideales o teóricos de fuerte carácter prescriptivo como ocurre con el principio de "modernidad". En las últimas décadas se ha rebatido la comprensión de América Latina como un espacio arcaico, autoritario y corporativo a causa de la herencia colonial y se han construido consensos historiográficos ${ }^{3}$ respecto a una ciudadanía definida desde presupuestos fuertemente inclusivos, una sociedad civil altamente politizada y un exceso de experimentación democrática a partir del debate sobre el modelo de Estado y las competencias institucionales de los sujetos políticos. Pese a ello, aún se mantiene que los países recién emancipados no satisfacían los requisitos de "modernidad" con el argumento de la falta de uniformidad étnica, normativa e institucional ${ }^{4}$. Ésta se debía a la supervivencia de la heterogeneidad del cuerpo social y político del período procedente; lo que se tornaba en un serio obstáculo para la existencia nacional al hacer de la estabilidad y centralidad políticas un sinónimo de gobernabilidad. En respuesta, este dossier cuestiona la naturalización de la "modernidad" a partir de un modelo que parte de una presunción acerca de cómo debería producirse la inserción del individuo en la sociedad y del tipo de gobierno que debería erigirse sobre dicha relación, ya que ello comporta una visión monolítica, teleológica y unívoca acerca de las nociones de individuo, sociedad y gobierno y acerca de las relaciones establecidas entre ellos. Se aboga, así, por repensar los procesos políticos decimonónicos en América Latina desde una triple óptica ligada al debate entre individuo y comunidad:

${ }^{3}$ Al respecto véanse los trabajos colectivos: Carmagnani, 1987; AnNino - Castro Leiva - Guerra, 1994; Annino, 1995; Malamud - González - Irurozqui, 1995; SÁbato, 1999; Posada-Carbó, 1997; Malamud, 2000; Forment, 2003; IrurozQui, 2004; Colom, 2006; Malamud - Dardé, 2004; Chartier FEROS, 2006.

${ }^{4}$ Esta perspectiva se está desarrollando prioritariamente por estudios que plantean la uniformización legal y jurisdiccional como pautas imprescindibles para la modernización nacional. Ejemplo de ello es el monográfico RoJAs, 2006. 
primero, una comprensión compleja del liberalismo ${ }^{5}$ debido a que si bien éste remite a derechos ello no implica necesariamente individualismo ${ }^{6}$; segundo, la recuperación de los cuerpos intermedios como ámbitos de adscripción identitaria que no tenían que entrar obligatoriamente en conflicto con la lealtad y fidelidad nacionales 7 ; y, tercero, el cuestionamiento de la cadena liberalismo-democracia-gobernabilidad ${ }^{8}$.

Con el fin de subrayar la complementariedad entre la justicia y la violencia política y asumir la heterogeneidad social compatible con los procesos de modernidad, se ofrece una lectura del Estado como una institución dinámica con capacidad de adaptación y reconstitución, que combate la visión dicotómica según la cual el poder estatal se impone a una sociedad que se resiste. Para dar cuenta de la interacción permanente entre la sociedad y el Estado es preciso establecer qué se entiende por institución y qué significado tiene la acción de institucionalizar el Estado. A partir de los trabajos de Georges Gurvitch, Félix Guattari y René Lourau', se propone contestar esta pregunta recurriendo al origen semántico del concepto. Institución remite a la acción de instituir, esto es, de fundar y crear un orden nuevo sobre uno antiguo. Tal contenido presenta a la institución como un producto polisémico, dinámico y multifuncional que remite tanto a lo instituido como a lo instituyente. Lo primero hace mención al orden establecido y a las normas vigentes, mientras lo segundo alude a aquello por cuyo intermedio algo acontece, tiene lugar y origina sentido. En consecuencia, institución, en tanto combinación de lo instituido y lo instituyente implica a la vez permanencia y acto/intervención. Esta concepción hace que una institución no sea anterior y trascendente a los grupos humanos ni tampoco sea inmanente a la vida social. Hace referencia a una norma, una forma social o una representación, pero también señala a la actividad desplegada por los miembros de la sociedad en tanto usuarios de tales normas, formas sociales o representaciones. Y ello permite que toda institución esté conformada por fenómenos de poder, sistemas de acción, de decisión, de control y de negociación.

Así, frente a una lectura de las instituciones como normas universales, ideología o modalidad psicológica de interiorización de las normas, este dossier se decanta por una definición que incide en que el dinamismo de la acción social interviene en un movimiento de ida y vuelta en la conformación institucional. De manera que, tal como propone Mary Douglas ${ }^{10}$, el pensamiento de los individuos queda ligado a las instituciones que rigen sus vidas en la medida en que su construcción y posterior legitimidad es resultado de la adaptación dinámica a una forma común de las ideas discordantes de dichos sujetos. En virtud de lo anterior, la institucionalización o acto de institucionalizar se asume como producto de la interacción entre la racionalidad

\footnotetext{
${ }^{5}$ Se resalta la importancia del ciclo de conferencias sobre el liberalismo en América Latina organizado por Pedro Pérez Herrero, primero en la Fundación Ortega y Gasset, y después en la Universidad de Alcalá de Henares.

${ }^{6}$ BIRD, 2004.

7 De Francisco, 2007; Arteta, 2008; Villaverde, 2008.

${ }^{8}$ Sartori, 2005; Agulhon, 1979; Barbalet, 1988; Tilly, 1996.

${ }^{9}$ Gurvitch, 1955, pp. 3-44; Guattari, 1965, pp. 91-108; Lourau, 1994, pp. 9-11, 140-144, 159, 169, 188.

${ }^{10}$ Douglas, 1996.
} 
establecida -reglas, formas sociales o códigos- y los acontecimientos, desarrollos, movimientos sociales que se apoyan implícita o explícitamente en dicha racionalidad y/o la cuestionan. Y da cuenta del proceso por el que se crean sistemas de pertenencias y de referencias múltiples con respecto a modos de organización del tiempo y del espacio sociales.

A partir de una comprensión dual de la institución -lo instituido y lo instituyentese sostienen tres ideas sobre los procesos de estatalidad: primero, son multidireccionales; segundo, se ponen en práctica y se recrean en diversos niveles de interacción social; y, tercero, resultan inconclusos en la medida en que en su formación y aplicación intervienen siempre poderes que, en mayor o menor medida, desactivan su interrelación con la sociedad. Consecuencia de ello es que los límites entre Estado y sociedad son vistos como productos y efectos del poder, concibiéndose las resistencias como negociaciones y reacomodos. Por ello en este dossier se aboga por un acercamiento al Estado desde su complejidad socio-institucional, entendiéndolo como una construcción producto de procesos políticos y sociales que una vez instituidos por la sociedad instituyente conforman los límites estructurales de ésta, pudiendo éstos volver a transformarse gracias a su accionar público. El Estado en tanto institución no estaría antes o después de la sociedad, pues actúa como un elemento fundador de la misma que al mismo tiempo es fundado por ella, garantizando su existencia institucional la vida de otras instituciones a través de múltiples pactos. En consecuencia se define al Estado como un conjunto de entramados institucionales y organizativos formales e informales que se construyen en continuos procesos de negociación, disputa y acuerdos entre grupos específicos de actores ${ }^{11}$.

Con el objetivo de materializar un enfoque analítico que subraya la interacción permanente entre la sociedad y el Estado y que percibe, por tanto, al Estado como una institución con capacidad de adaptación y reconstitución, este dossier se centra en los fenómenos de la justicia y la violencia política. Desde una perspectiva historiográfica, el primero ha experimentando una profunda transformación en las últimas décadas debido al giro dado en la interpretación de la ley y del derecho. Frente a una consideración impositiva, coercitiva o limitadora de la ley, actualmente se están desarrollando estudios que tratan de incardinar la creación de la ley y su aplicación con las realidades sociales. El carácter regulador inherente a la norma ya no se vincula solo con la capacidad restrictiva y dirigista de la autoridad sobre la acción humana, sino también con la idea de ordenación de las conductas sociales con el fin de garantizar la convivencia en sociedades políticas. Asimismo, el derecho se entiende como instrumento que permite la realización del individuo al tiempo que define un campo de acción legítimo (limitado) para el gobierno ${ }^{12}$. Se sutura, así, la fractura entre sociedad y Estado en lo referente a la ley desde la otra cara de la moneda, recomponiendo la posible intervención de los ciudadanos en la construcción del Estado de derecho.

${ }^{11}$ Esta definición ha sido elaborada en contraposición o a partir de los textos de: WeBer, 1984; Remond, 1988; Abrams, 1988; Hall - Ikenberry, 1993; Peralta - Irurozqui, 2000, pp. 13-30; Bloom - Stepptat, 2001; IrurozQui, 2005; Scharma - Gupta, 2006; Foucault, 2007; Barragán - Wanderley, 2009.

12 Villacañas, 1999; Grossi, 2006. 
El giro interpretativo mencionado se ha simultaneado con el auge en la disciplina histórica de la perspectiva política y, muy especialmente, con el desarrollo de una historia social de fuerte imbricación política. Ello ha convertido a la historia de la justicia en un campo de interés compartido por especialistas en historia social, historia del derecho e historia política, fomentando el intercambio de métodos, perspectivas y abordajes teóricos y dando lugar, en ocasiones, a propuestas heterodoxas muy sugerentes. En este contexto general, los clásicos estudios centrados en los procesos de codificación o en la construcción de las grandes instituciones de administración de justicia desde una perspectiva fuertemente descriptiva conviven con una proliferación de enfoques que refuerzan ese carácter múltiple de la ley. Con ello la sacan de un ámbito autónomo y ajeno a una realidad social y política y destacan su implicación en un complejo y amplio proceso de transformación permanente. El resultado son estudios sobre el proceso político de construcción de la ley y la interacción social en su aplicación que abordan las temáticas relacionadas con la recomposición de la cultura jurisdiccional hispana y con la (re)organización de la administración de justicia a partir de la crisis de 1808 y vinculada con los procesos emancipadores y la creación de las nuevas repúblicas ${ }^{13}$.

Si el tema de la justicia ha sido una de las causas pendientes de la historiografía latinoamericana, el de la violencia resulta recurrente sin que ello implique un certero conocimiento sobre el mismo ${ }^{14}$. Al contrario, se trata de un campo de estudio preñado de tópicos negativos que lo han definido como un mal endémico asociado a la experiencia colonial y a las oligarquías republicanas entreguistas y como una de las principales circunstancias desestabilizadoras de la construcción nacional. En respuesta a esa visión nociva de la violencia política los estudios asociados a la nueva historia política e historia social de lo político han evitado su asimilación con el caos, el desorden, la irracionalidad y la ausencia de normas o de formas sociales, su vinculación a una sociedad corrupta o imperfecta o su reducción a un mero instrumento estatal. Sin negar la presencia de la violencia en el devenir político y social latinoamericano, en los últimos años la historiografía se ha centrado en mostrar que dicho fenómeno está presente en toda sociedad, que es un modo de acción social y que actúa como un instrumento de la construcción democrática. Se ha insistido en su carácter fundador de órdenes sociales y de nuevas identidades públicas, acelerador o modificador de la dinámica social y de los sistemas sociales y favorecedor de la cohesión social. Esto sucede debido a que genera acciones relacionales que, al forzar la modificación de un comportamiento público, provocan una constante interacción social ligada inexorablemente al problema del poder ${ }^{15}$.

Resultado de ello ha sido la comprensión de las guerras civiles, revoluciones, rebeliones, revueltas o los golpes de Estado como acontecimientos generadores de modernidad a través de los que fue posible generar un tejido nacional. En consecuencia, la violencia política es entendida como un recurso disponible por los contendientes

\footnotetext{
${ }^{13}$ Se remite al artículo de Mirian Galante para las aportaciones bibliográficas sobre el tema.

${ }^{14}$ Para un conocimiento bibliográfico sobre el tema se remite al estado de la cuestión de GonzÁLeZCalleja, 2002 y al dossier de IrurozQui, 2009.

${ }^{15}$ Maffesoli, 1978, pp. 23-31; Braud, 2004, pp. 46-48.
} 
en un proceso destinado a frenar, acelerar o precipitar el cambio social o político. Cuatro son las principales perspectivas de trabajo: primera, el papel de las instituciones militares -ejército, guardias nacionales, milicias, etc.- en la fundación, la legitimación y el fortalecimiento de las nuevas naciones; segunda, la importancia de la guerra en la definición del modelo de Estado y en la estructuración de la nación a través de instituciones legales; tercero, las transformaciones identitarias generadas por los escenarios bélicos; y, cuarto, la noción de "ciudadanía armada" y la militarización constitucional y cívica de la sociedad. Estas perspectivas pueden sintetizarse como el estudio de los hechos violentos de intencionalidad políticosocial que convocan a un grupo de individuos en torno a instancias o aspiraciones de poder ${ }^{16}$.

Son cinco los artículos que conforman este dossier, abordando todos ellos la primera mitad del siglo XIX. Los de Alejandro Londoño y Edwin Monsalvo/Jorge Conde asumen el caso colombiano. El primero trata el tema de la cultura jurídica a partir del estudio de la procedencia, la circulación, la recepción y el uso de obras jurídicas, tanto extranjeras como nacionales, durante los primeros años republicanos. Su intención es poner en valor una literatura apenas tenida en cuenta, pero fundamental en la comprensión del bagaje sociocultural de los letrados de la época. Los segundos se centran en una supuesta conspiración acaecida el 14 de agosto de 1833 en la ciudad de Cartagena. A partir de su proceso judicial no solo muestran la adscripción sociolaboral de los implicados, sino también el peso de la invención de conatos subversivos y del discurso del miedo racial en el control político de las acciones sediciosas. Marta Irurozqui y Federica Morelli han escogido, respectivamente, los territorios que hoy se conocen por Bolivia y Ecuador. Para la primera autora, la represión militar juntista de 1810 en la Audiencia de Charcas remite a un doble conflicto intracontinental de autoridad e influencias jurisdiccionales: entre los virreyes e intendentes frente a otros cuerpos como la audiencia y el cabildo; y entre los virreinatos del Río de La Plata y del Perú. De esa acción violenta refrendada en un proceso judicial resultó, de un lado, la pérdida de la posibilidad de que una institución delegativa real -la audiencia- asumiera legítimamente la soberanía indivisa, y, de otro, la dispersión de la misma a través de los cabildos. Municipalismo, justicia local y milicias permiten a Morelli discutir sobre el alcance político de un modelo de administración de justicia en el que prevaleció la impronta de la codificación española. Su peso unido al influjo del municipalismo gaditano y a la dinámica de la guerra independentista favoreció en Ecuador un contexto judicial republicano sujeto a dos autonomías: la local municipal con la figura del alcalde juez y la del fuero militar con la figura del caudillo. Por último, Mirian Galante ofrece una reflexión historiográfica construida a partir de los temas, interpretaciones y problemáticas que se trabajan actualmente desde la historia de la justicia. $\mathrm{Su}$ intención es mostrar cómo todos ellos contribuyen a replantear algunos de los presupuestos fetiche del proceso de construcción política del siglo XIX. En este sen-

16 Textos colectivos pioneros sobre el tema: CARMagnani, 1993; Posada-CARbó, 1995; Earle, 2000; Dunkerley, 2002; Escobar - Falcón, 2002; SÁnchez - Lair, 2003; SÁbato - Lettieri, 2003; Malamud - Dardé, 2004; Chust - Marchena, 2008; MÉndez, 2006. Una visión historiográfica general sobre el tema en la Presentación del dossier IruRozQui, 2009. 
tido, el trabajo de Galante vendría a completar o matizar algunas de las afirmaciones sostenidas en esta presentación.

Aunque los temas de justicia y de violencia política demuestran ser centrales en el estudio sobre la construcción nacional, la reciente relevancia historiográfica alcanzada por la historia jurídica ha favorecido un activo diálogo disciplinar e interdisciplinar que ha obligado a replantear temas sobre los que se creían alcanzados consensos. El mito de la imparcialidad de la ley, la dicotomía entre los principios legales consuetudinario y positivo, la idealización del modelo estatal francés, las características del Estado moderno o del Estado liberal, la polisemia del liberalismo, la relación entre sociedad y Estado o el nexo entre la política y la justicia son de nuevo objeto de discusión como lo muestran las contradictorias conclusiones que contienen los artículos de este dossier. Dejando de lado el disenso, en general puede afirmarse que los cinco artículos apuntan a una comprensión del Estado en su triple dimensión de materialidad/agente, prácticas políticas y representación/discurso, siendo subrayadas sus dos principales facetas. Por un lado, su especial condición de institución que garantiza la existencia de otras a través de múltiples pactos; por otro, su autocomprensión como la principal entidad autónoma por lo que debe actuar para asegurar su liderazgo frente a otros poderes que puedan cuestionarlo. Asimismo, en lo relativo a la relación entre justicia y violencia política, los textos del dossier sostienen que esta última fue un recurso político para asentar el imperio de la ley como eje de la gobernabilidad republicana, que la ley servía para gestionar las situaciones de violencia y que su adscripción al Estado hacía que la sociedad convirtiese a éste en el mediador por excelencia en la resolución de los conflictos. Todo ello fomentaba la implicación de la sociedad en la construcción del Estado, contribuyendo a la legitimación social del mismo. Ello entrañaba también una paradoja. Aunque muchas instituciones públicas nacían del ejercicio político de la violencia debían terminar por conjurarla para edificar un orden estable a través de los procesos de estatalización. Tal acción implicaba un contradictorio hermanamiento entre violencia y ley, al generar la primera una construcción polémica del orden y la segunda un asentamiento reglado del mismo.

\section{REFERENCIAS BIBLIOGRÁFICAS}

ABrams, Phillip

1988 "Notes on the Difficulthy the State". Journal of Historical Sociology. Oxford, New York. $n^{\circ}$ 1: 1, pp. 58-89.

Agulhon, Maurice

1979 La Rèpublique au village. Les populations du Var de la Rèvolution à la seconde Rèpublique. Paris. Le Seuil.

AnNino, Antonio (coord.)

1995 Historia de las elecciones en Iberoamérica, siglo XIX. Buenos Aires. Fondo de Cultura Económica. 
Annino, Antonio; Castro Leiva, Luis y Guerra, François Xavier (dirs.)

1994 De los imperios a las naciones: Iberoamérica. Zaragoza. Ibercaja.

Arteta, Aurelio (ed.)

2008 El saber del ciudadano. Las nociones capitales de la democracia. Madrid. Alianza Editorial.

BARBALET, Jack M.

1988 Citizenship. Rights, Struggle and Class Inequality. Milton Keynes. Open University.

BarRagán, Rossana y Wanderley, Fernanda

2009 "Etnografías del Estado". Presentación del Dossier Etnografías del Estado en América Latina. Iconos. Revista de Ciencias Sociales. Quito. $\mathrm{n}^{\mathrm{o}} 34$, pp. 21-25.

BIRD, Colin

2004 The Myth of Liberal Individualism. Cambridge. Cambridge University Press.

Bloom, Thomas y Stepputat, Finn

2001 States of Imagination. Durham. Duke University Press.

BRAUD, Phillip

2004 Violencias politicas. Madrid. Alianza Editorial.

Carbonell, Miguel; Orozco, Wistano y Vázquez, Rodolfo (coords.)

2002 Estado de derecho. Concepto, fundamentos y democratización en América Latina. México. ITAM-CM-UNAM.

Carmagnani, Marcelo et al. (coords.)

1987 América Latina: dallo Stato coloniale allo stato nazione. Tomo I y II. Milano. Franco Angeli.

1993 Federalismos latinoamericanos. México, Brasil, Argentina. México. $\mathrm{CM}$ - Fondo de Cultura Económica.

Chartier, Roger y Feros, Antonio (dirs.)

2006 Europa, América y el mundo: tiempos históricos. Madrid. Fundación Carolina-Fundación Rafael del Pino-Marcial Pons.

Chust, Manuel y Marchena, Juan (eds.)

2008 Las armas de la Nación. Independencia y ciudadanía en Hispanoamérica (1750-1850). Madrid/Frankfurt. Iberoamericana Vervuert.

Colom, Francisco (coord.)

2006 La construcción de las identidades nacionales en el mundo hispánico. Ideas, lenguajes políticos e imaginarios culturales. México. Fondo de Cultura Económica. 
Douglas, Mary

1996 Cómo piensan las instituciones. Madrid. Alianza Editorial.

DUNKERLEY, James (ed.)

2002 Studies in the Formation of the Nation State in Latin America. London. ILAS.

EARLE, Rebecca (ed.)

2000 Rumors of Wars. Civil Conflicts in Nineteenth-Century Latin America. London. ILAS.

Escobar, Antonio y FALCÓn, Romana (coords.)

2002 Los ejes de la disputa. Movimientos sociales y actores colectivos en América Latina, siglo XIX. Frankfurt. Cuadernos de AHILA.

Forment, Carlos

2003 Democracy in Latin America, 1760-1900. Civic Selfhood and Public Life in Mexico and Peru. Chicago. Chicago University Press.

Foucault, Michel

2007 Seguridad, territorio, población. México. Fondo de Cultura Económica.

Francisco, Andrés de

2007 Ciudadanía y democracia. Madrid. Catarata.

GonzÁlez CAlleja, Eduardo

2002 La violencia en la política. Perspectivas teóricas sobre el empleo deliberado de la fuerza en los conflictos de poder. Madrid. Consejo Superior de Investigaciones Científicas.

Grossi, Paolo

2006 La primera lección de derecho. Marcial Pons. Madrid.

GuATtARI, Félix

1965 "La transversalité". Revue de Psychothérapie institutionelle. $\mathrm{n}^{\circ}$ 1, pp. 91-108.

GuRvitch, Georges

1955 "Le concept de Structure sociale". Cahiers Internatioanaux de Sociologie. Paris. $\mathrm{n}^{\circ}$ 19, pp. 3-44.

Hall, John A. y IKenBerRY, G. John

1993 El Estado. Madrid. Alianza Editorial.

IRUROZQUI, Marta

2004 La ciudadanía en debate en América Latina. Discusiones historiográficas y una propuesta teórica sobre el valor público de la infracción electoral. Lima. Instituto de Estudios Peruanos. 
IRUROZQUI, Marta (ed.)

2005 La mirada esquiva. Reflexiones históricas sobre la interacción del Estado y la ciudadanía en los Andes (Bolivia, Ecuador y Perú), siglo $X I X$. Madrid. Consejo Superior de Investigaciones Científicas.

IRUROZQUI, Marta (coord.)

2009 Violencia política en América Latina, siglo XIX. Dossier publicado en Revista de Indias. Madrid. n 246, pp. 17-184.

IruRozQui, Marta y Galante, Mirian

2011 Sangre de ley. Justicia y violencia política en la institucionalización del Estado en América Latina, siglo XIX. Madrid. Ed. Polifemo.

JACOBSEn, Nils y Aljovín de Losada, Cristóbal (ed.)

2005 Political Cultures in the Andes 1750-1950. Durham - London. Duke University Press.

LOURAU, René

1994 El análisis institucional. Buenos Aires. Amorrortu Editores.

MAFFESOLI, Michael.

1978 La violence fondatrice. Paris. Ed. Champ Urbain.

Malamud, Carlos; GonzÁlez, Marisa y IruRozQui, Marta

1995 Partidos políticos y elecciones en América Latina y la Península Ibérica, 1830-1930. Madrid. IUOYG.

MALAMUd, Carlos (coord.)

2000 Legitimidad, representación y alternancia en España y América Latina: las reformas electorales (1880-1930). México. Fondo de Cultura Económica.

Malamud, Carlos y Dardé, Carlos (eds.)

2004 Violencia y legitimidad. Política y revoluciones en España y América Latina, 1840-1910. Santander. Universidad de Cantabria.

MÉnDEZ, Cecilia

2006 Populismo militar y etnicidad en los Andes. Dossier publicado en Iconos. Revista de Ciencias Sociales. Quito. nº 26.

Peralta, Víctor y IruRozqui, Marta

2000 "Por la Fusión, la Concordia y el Unitarismo". Estado y caudillismo en Bolivia, 1826-1880. Madrid. Consejo Superior de Investigaciones Científicas.

Posada-CARBó, Eduardo (ed.)

1995 Wars, Parties and Nationalism. Essays on the Politics and Society of Nineteenth-Century Latin America. London. ILAS.

1997 Elections before Democracy. The History of Elections in Europe and Latin America. London. ILAS. 
REMOND, Rene

1988 Pour une histoire politique. Paris. Le Seuil.

RoJAs, Beatriz (coord.)

2006 "Ley y justicia (del virreinato a la posrevolución)". Historia mexicana. México. $n^{\circ}$ LV: 220, pp. 717-765.

SÁBATO, Hilda (coord.)

1999 Ciudadanía política y formación de las naciones. México. Fondo de Cultura Económica.

SÁBATO, Hilda y LetTiERI, Alberto (comps.)

2003 La vida política en la Argentina del siglo XIX. Armas, votos y voces. Buenos Aires. Fondo de Cultura Económica.

SÁNCHEZ, Gonzalo y LaIR, Eric (eds.)

2003 "De la necesidad de pensar la violencia colectiva: el caso de los países andinos". Bulletin de l'Institut Français d'Etudes Andines. Lima. ${ }^{\circ}$ 29/3, pp. 259-265.

SARTORI, Giovanni

2005 Elementos de teoría política. Madrid. Alianza Editorial.

Sharma, Aradhana y GuPTA, Akhil

2006 The Anthropology of the State. A reader. Malden. Blackwell Publishing.

TILLY, Charles (ed.)

1996 Citizenship, Identity and Social History. Cambridge. Cambridge University Press.

Villacañas Berlanga, José Luis

1999 Res publica. Los fundamentos normativos de la política. Madrid. Akal.

Villaverde Rico, María José

2008 La ilusión republicana. Ideales y mitos. Madrid. Tecnos.

WeBER, Max

1984 Economía y sociedad. Esbozo de la sociología comprensiva. México.

Fondo de Cultura Económica. 